\title{
ANALYSIS OF THE MOTION OF THE LOAD CARRIED BY A LABORATORY MOBILE CRANE
}

\author{
D. Cekus* , P. Kwiatońn ${ }^{* *}$
}

\begin{abstract}
The paper is an extension of previous authors' works, in which the simulation model of a laboratory mobile crane was developed. The simulation model allowed to track the trajectory of the load carried on a flexible or rigid rope. The load was treated as a particle. In this work, the theoretical and the computational models were formulated to simulate the motion of a load represented in the form of a rigid body whose parameters can be freely defined. The numerical program allows one to analyze the dynamic phenomena both during the working cycle and the free movement of the load.
\end{abstract}

Keywords: multi-body dynamics, load, mobile crane, modeling, simulation

\section{Introduction}

The load carrying process is an important problem during the analysis of the dynamics of mobile cranes. Knowledge of the behavior of the mobile crane during a work cycle is useful at the stage of designing a new construction, improving existing ones, as well as positioning and minimizing final load fluctuations. Literature about the truck crane and the influence of external factors on its dynamic behavior was discussed in the doctoral thesis by Cekus (2005). A summary of the results obtained in reference to the mobile cranes can be works (Jedliński \& Grzesikiewicz, 1990; Posiadała et al., 2005; Trombski et al., 1990). Jedliński \& Grzesikiewicz (1990) described dynamic phenomena occurring in the mathematical model during the hoisting of the load (only in the lifting plane). Trombski et al. (1990) presented two dynamic models. The first model was concerned on the spatial rotary motion, and the second one involved the planar motion in the lifting plane. Posiadała et al. (2005) have developed a mathematical description of the movement of the system rotary crane - load during the duty cycle. The problem of positioning and minimization of the final load fluctuations in truck cranes was presented, among others, in (Abdel-Rahman \& Nayfeh, 2002; Kłosiński, 2005; Maczyński, 2003). Abdel-Rahman \& Nayfeh (2002) proposed to reduce payload (a pointmass) pendulations using the reelingand unreeling of the hoisting cable. Kłosiński (2005) presented the method that allows one to transfer the payload from one point to a target point, with simultaneous minimization of the swings when the working motion was finished (the experimental verification has been conducted). Maczyński (2003) selected the driving function (with feedback and the PID controller) of the body rotation, which allows one to stabilize the position of the load. In all mentioned papers the load was treated as a particle. The load was modeled as a 3D rigid body by Grabski \& Strzałko (2003), but only the initial period of the crane operation (rope tensioning, stick-slip motion of the load with respect to the ground, the moment of detachment and motion of the load after is detachment) was described.

This work presents the behavior of the load carried by a laboratory mobile crane. Numerical investigations were carried out on a modified simulation model (Cekus et al., 2014). The modification of the system consists in replacing the load treated as a particle by a rigid body. The simulations comprise an

\footnotetext{
Assoc Prof. Dawid Cekus Phd. Eng., Institute of Mechanics and Machine Design Fundamentals, Czestochowa University of Tehnology, Street Dąbrowskiego 73; 42-201, Częstochowa; PL， cekus@imipkm.pcz.pl

** M.Sc. Eng. Paweł Kwiatoń, Institute of Mechanics and Machine Design Fundamentals, Czestochowa University of Tehnology, Street Dąbrowskiego 73; 42-201, Częstochowa; PL， kwiaton@imipkm.pcz.pl
} 
influence of drive and control systems on the payload motion. The sample of numerical results illustrates the trajectory and positions of the load carried on the flexible rope.

\section{Simulation model}

The simulation model (Fig. 1) was created as a result of implementation of a geometrical model made in the SolidWorks in the Matlab/Simulink environment. The detailed process of construction of the analyzed model was shown in paper (Cekus et al., 2014). In this work, the particle has been replaced by a rigid body (Fig. 1b). Therefore, it was necessary to define the orientation of the movable Cartesian coordinate system $C$ relative to the global one. The Bryant's angles (Flores, 2015) ( $\Psi, \Theta, \Phi)$ were used to describe the rigid body (the load) orientation. Using these angles, it is possible to determine the angular velocities and accelerations of the rotation of the rigid body associated with the moving coordinate system.

a)

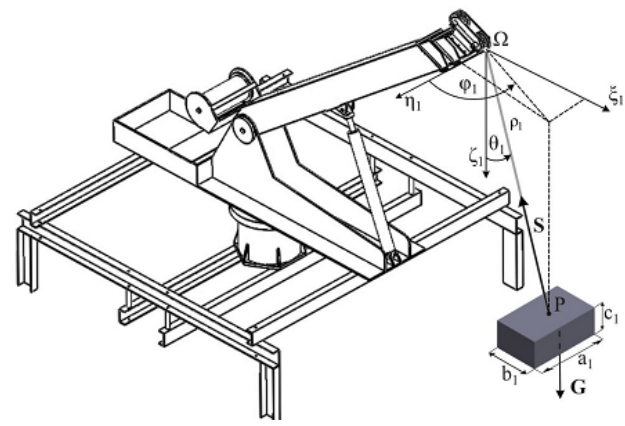

b)

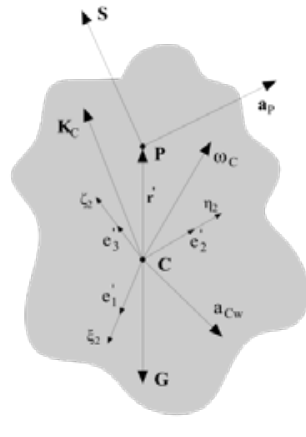

Fig. 1: Simulation model of laboratory truck crane: a) computational model, b) forces acting on the load

The general motion of a rigid body can be presented as a resultant of a translational motion of a center of mass and a rotation about a fixed point about a center of mass. Rotation about a fixed point can be described by the vector equation (Posiadała \& Tomala, 2011):

$$
\mathbf{M}_{\mathrm{C}}=\frac{d}{d t} \mathbf{K}_{\mathrm{C}},
$$

where: $\mathbf{K}_{\mathbf{C}}$ is a vector of a total angular momentum of a rigid body relative to the center of its mass expressed as the product of the moments of inertia matrix and the absolute angular velocity of body rotation around its center of mass.

Using the second law of Newton's dynamics, the vector of moments acting on a solid body relative to the center of mass can be written as:

$$
\mathbf{M}_{\mathrm{C}}=\mathbf{r} \times \mathbf{F},
$$

where: $\mathbf{F}$ is a vector sum of the tension in the rope $\left(\rho_{l}\right)$ and the force of inertia of the load.

The equation (1), taking into account the derivative of the total angular momentum of a solid in the constant system, leads to a system of dynamic equations of motion that can be written by applying the Einstein's summation convention (Posiadała \& Tomala, 2011):

$$
M_{j}=J_{j m} \varepsilon_{m}+\varepsilon_{j k m} \omega_{k} J_{m n} \omega_{n}, \quad j=1,2,3,
$$

where: $\mathbf{J}$ is the moments of inertia matrix, and $\varepsilon_{j k m}$ is Levi-Civita symbol.

The components of angular velocity and angular acceleration vectors, in system of equations (3), are presented as functions of Bryant's angles and their partial derivatives. Taking into account: the total velocity and the total acceleration of the solid in the constant system (Posiadała \& Tomala, 2011), the components of the moments and their transformations, as well as the vectors of forces acting on the load, the system of three second order differential equations is obtained:

$$
\mathrm{DZ}=\mathrm{E} .
$$

In order to solve the initial problem of the movement, the formulas should be reduced to the system of first order differential equations by the following substitutions:

$$
Z_{1}=\Psi_{1}, Z_{2}=\Theta_{2}, Z_{3}=\Phi_{3}, Z_{4}=\dot{\Psi}_{1}, Z_{5}=\dot{\Theta}_{2}, Z_{6}=\dot{\Phi}_{3} .
$$

Taking into account the system of equations of load motion (Cekus et al., 2014): 


$$
\begin{aligned}
& \ddot{\xi}=-a_{\Omega Z}+\frac{\xi}{\rho_{I}{ }^{2}}\left[\rho_{I} *\left(\ddot{\rho}_{l}+\ddot{\bar{\rho}}_{l}\right)+\left(\dot{\rho}_{I}+\dot{\bar{\rho}}_{l}\right)^{2}+\xi a_{\Omega Z}+\eta a_{\Omega X}+\zeta\left(a_{\Omega Y}+g\right)-(\dot{\xi}+\dot{\eta}+\dot{\zeta})\right], \\
& \ddot{\eta}=-a_{\Omega X}+\frac{\eta}{\rho_{I} *^{2}}\left[\rho_{I} *\left(\ddot{\rho}_{l}+\ddot{\bar{\rho}}_{l}\right)+\left(\dot{\rho}_{l}+\dot{\bar{\rho}}_{l}\right)^{2}+\xi a_{\Omega Z}+\eta a_{\Omega X}+\zeta\left(a_{\Omega Y}+g\right)-(\dot{\xi}+\dot{\eta}+\dot{\zeta})\right], \\
& \ddot{\zeta}=a_{\Omega Y}+g+\frac{\zeta}{\rho_{l} *^{2}}\left[\rho_{l} *\left(\ddot{\rho}_{l}+\ddot{\bar{\rho}}_{l}\right)+\left(\dot{\rho}_{l}+\dot{\bar{\rho}}_{l}\right)^{2}+\xi a_{\Omega Z}+\eta a_{\Omega X}+\zeta\left(a_{\Omega Y}+g\right)-(\dot{\xi}+\dot{\eta}+\dot{\zeta})\right], \\
& \ddot{\bar{\rho}}=-\frac{1}{\rho_{I}{ }^{*}}\left[\rho_{I} *\left(\ddot{\rho}_{I}+\ddot{\bar{\rho}}_{l}\right)+\left(\dot{\rho}_{l}+\dot{\bar{\rho}}_{l}\right)^{2}+\xi a_{\Omega Z}+\eta a_{\Omega X}+\zeta\left(a_{\Omega Y}+g\right)-(\dot{\xi}+\dot{\eta}+\dot{\zeta})\right]-\frac{c_{l}}{m} \dot{\bar{\rho}}_{l}-\frac{k_{l}}{m} \bar{\rho}_{l}-g \frac{\zeta}{\rho_{l}{ }^{*}},(
\end{aligned}
$$

where: components $a_{\Omega X}, a_{\Omega Y}, a_{\Omega Z}$ are the accelerations of the end of the boom in the global system, a system of equations of load (in the form of a rigid body) motion is obtained.

Systems of equations $(4,6)$ are supplemented with initial conditions in the following form:

$$
\begin{array}{r}
\left.\xi(t)\right|_{t=0}=\xi_{0},\left.\dot{\xi}(t)\right|_{t=0}=\dot{\xi}_{0},\left.\eta(t)\right|_{t=0}=\eta_{0},\left.\dot{\eta}(t)\right|_{t=0}=\dot{\eta}_{0},\left.\zeta(t)\right|_{t=0}=\zeta_{0},\left.\dot{\zeta}(t)\right|_{t=0}=\dot{\zeta}_{0},\left.\bar{\rho}_{l}(t)\right|_{t=0}=\bar{\rho}_{l 0},\left.\dot{\bar{\rho}}_{l}(t)\right|_{t=0}=\dot{\bar{\rho}}_{l 0}, \\
\left.\Psi(t)\right|_{t=0}=\Psi_{0},\left.\dot{\Psi}(t)\right|_{t=0}=\dot{\Psi}_{0},\left.\Theta(t)\right|_{t=0}=\Theta_{0},\left.\dot{\Theta}(t)\right|_{t=0}=\dot{\Theta}_{0},\left.\Phi(t)\right|_{t=0}=\Phi_{0},\left.\dot{\Phi}(t)\right|_{t=0}=\dot{\Phi}_{0} \quad \text { (7a-n) }
\end{array}
$$

what leads to the final initial problem formulation of the movement of a load carried on a flexible rope. The above equations have been entered in the form of scripts and functions into the SimMechanics model.

\section{Sample numerical results}

Exemplary simulations (Fig. 3) were performed for three rigid bodies $\left(a_{1}=b_{1}=c_{1}=0.5 \mathrm{~m} ; a_{2}=0.8 \mathrm{~m}\right.$, $b_{2}=0.5 \mathrm{~m}, c_{2}=0.3125 \mathrm{~m} ; a_{3}=1.6 \mathrm{~m}, b_{3}=0.5 \mathrm{~m}, c_{3}=0.15625 \mathrm{~m}$ ) representing a load with the same mass (50 kg) carried on a flexible rope. The initial length of the rope $\left(\rho_{l_{0}}\right)$ is $1.5 \mathrm{~m}$ (length is measured from the end of the boom to the hook up point of the load). The movement began from zero initial conditions, except for $\eta\left(t_{0}\right)=0.5 \mathrm{~m}$ and $\zeta\left(t_{0}\right)=\rho_{0}$. The motion of the lifted load was considered for the time equal 50s. For the first 40s, the motion was forced by the controls and, after their action ceased, for the next 10s free oscillations of the lifted load were observed. The assumed motion sequences were directly connected with the working movements of the laboratory truck crane (linear motions are realized by the hydraulic cylinders (Uzny et al., 2016), while angular motions by the circulating cam hydraulic motors) and they resulted from control of: rotation of platform (start $=0 \mathrm{~s}$, stop $=10 \mathrm{~s}$, maximal velocity $=0.2 \mathrm{rad} / \mathrm{s}$ ), the boom inclination angle ( $\mathrm{start}=10 \mathrm{~s}$, stop $=20 \mathrm{~s}$, maximal velocity $=0.04 \mathrm{~m} / \mathrm{s}$ ), the rope length which depends on the rope motion forced by the winch (start $=30 \mathrm{~s}$, stop $=40 \mathrm{~s}$, maximal velocity $=0.1 \mathrm{~m} / \mathrm{s}$ ) and finally from the changes in the boom length (start $=20 \mathrm{~s}$, stop $=30 \mathrm{~s}$, maximal velocity $=0.1 \mathrm{~m} / \mathrm{s}$ ). All control functions were trapezoid pulses and included start-up (0.5 s), steady and braking ( $0.5 \mathrm{~s})$ states.

The initial problem has been solved with the help of the ode 45 function available in Matlab/Simulink program.
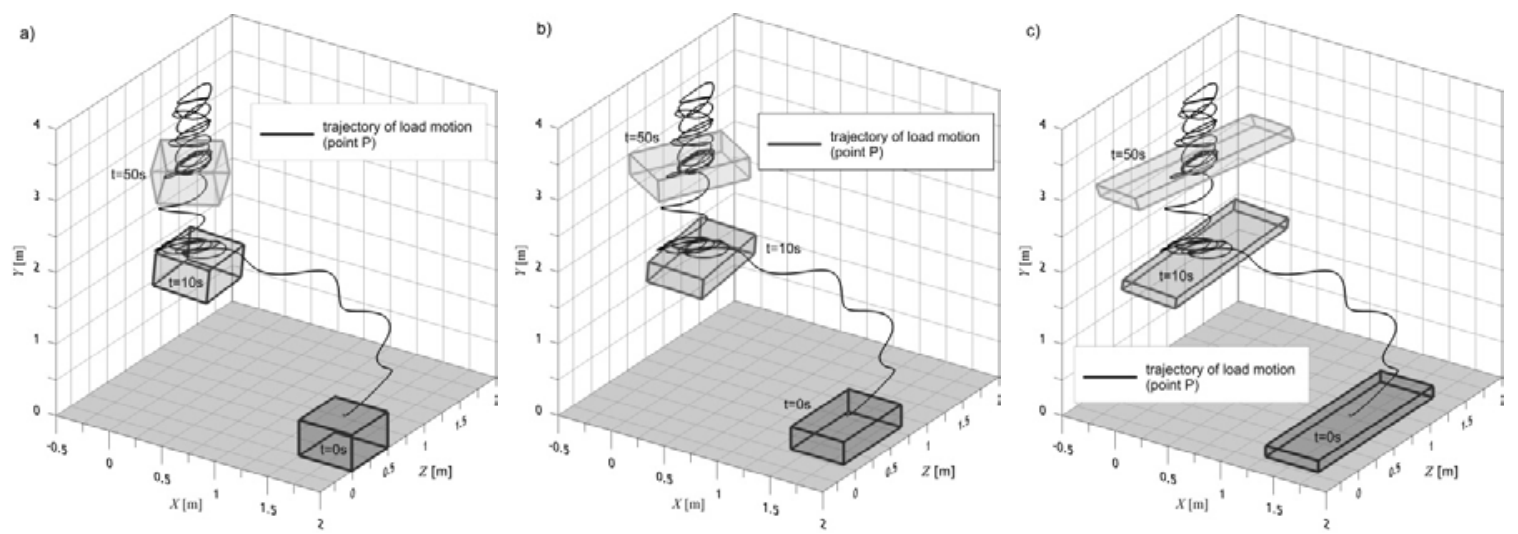

Fig. 2: Trajectory of load movement and its orientation in space in $0 \mathrm{~s}, 10 \mathrm{~s}, 50 \mathrm{~s}$ of the working cycle: a) rigid body 1, b) rigid body 2, c) rigid body 3

Based on the performed tests, it can be concluded that the different dimensions of the load (but with the same mass) does not affect on the trajectory of the suspension point (lifting sling). However, the attitude of the rigid body in the subsequent moments of time is different. This is very important when the load is 
positioned and it indicates that the load should not be considered as a particle but as a rigid body with the shape required to be transferred.

\section{Conclusions}

This paper describes a modified theoretical and computational models that allows one to simulate a load movement carried by a laboratory mobile crane. Load was treated as a rigid body. The effect of wind or friction forces on the load was omitted in the work, however, the inertia forces were taken into account. The influence of load dimensions on its fluctuations was analyzed. In the dynamic calculations, the influence of drive systems and control as a kinematic excitations in the form of trapezoid pulses were assumed. On the basis of conducted analyses, it has been stated that during the positioning of carried load, one cannot take into consideration load as the particle but as the rigid body. The presented model can be directly used to assess the stability of the truck crane during the duty cycle (Kacalak et al., 2018; Sochacki, 2007). The simulation model will be further developed by considering the friction forces in the joints and the influence of external factors such as wind power. Moreover, the kinematic excitations can be replaced by impact of power transmission and control systems. On the basis of those changes it is possible to get the feedback, positioning and fluctuations reduction of the load carried by crane.

\section{Acknowledgement}

The study has been carried out within statutory research of the Institute of Mechanics and Machine Design Fundamentals of Czestochowa University of Technology.

\section{References}

Abdel-Rahman, E.M. and Nayfeh, A.H. (2002) Pendulation reduction in boom cranes using cable length manipulation. Nonlinear Dynamics, 27, pp. 255-269.

Cekus, D. (2005) Dynamics of a rotary crane including tranverse-deformability of telescopic boom as well as longitudinal-deformability of telescopic cylinder and support hydraulic cylinders. Doctoral dissertation, Czestochowa (in Polish).

Cekus, D., Posiadala, B. and Waryś P. (2014) Integration of modeling in SolidWorks and Matlab/Simulink environments. Archive of Mechanical Engineering, Volume 61, Issue 1, pp. 57-74.

Flores. P. (2015) Concepts and Formulations for Spatial Multibody Dynamics. Springer Briefs in Applied Sciences and Technology.

Grabski J., Strzałko J. (2003) Dynamic analysis of the load hoisting process. Journal of Theoretical and Applied Mechanics, 41 (4), pp. 853-872.

Jedliński, W. and Grzesikiewicz, W. (1990) Dynamics of executive elements of working machines including control on the example of a telescopic crane. Scientific Works CPBP 02.05, Publisher of Warsaw University of Technology, Warsaw (in Polish).

Kacalak, W., Budniak, Z. and Majewski, M. (2018) Stability Assessment as a Criterion of Stabilization of the Movement Trajectory of Mobile Crane Working Elements. International Journal of Applied Mechanics and Engineering, 23(1), pp.65-77.

Kłosiński, J. (2005) Swing-free stop control of the slewing motion of a mobile crane. Control Engineering Practice, 13, pp. 451-460.

Maczyński, A. (2003) Load positioning and minimization of load oscillations in rotary cranes. Journal of Theoretical and Applied Mechanics, 41(4), pp. 873-885.

Posiadała, B., Cekus, D., Geisler, T., Kukla, S., Przybylski, J., Sochacki, W. and Wilczak, R. (2005) Modeling, model identification and dynamics research of mobile cranes. WNT, Scientific and Technical Book Foundation, Warsaw (in Polish).

Posiadała, B. and Tomala, M. (2011) The computational model of the movement of a load carried by a two-part gripper system. Modelling in Engineering, 41, pp. 323-330 (in Polish).

Sochacki, W. (2007) The dynamic stability of a laboratory model of a truck crane. Thin-walled Structures, 45 (1011), pp. 927-930.

Trombski, M., Wojciech, S., Harlecki, A., Kłosiński, J., Kłosowicz, M., Majewski, L., Suwaj, S. and Mihulowicz, A. (1990) Optimization of the truck crane support system as a part of the automatic system of working movements. Scientific Works CPBP 02.05, Publisher of Warsaw University of Technology, Warsaw (in Polish).

Uzny, S., Sokol, K., Kutrowski, L. (2016) Stability of a Hydraulic Telescopic Cylinder Subjected to Euler's Load. Proceedings of the 13th International Scientific Conference: Computer Aided Engineering, Book Series: Lecture Notes in Mechanical Engineering, pp. 581-588. 